\title{
Osteoconductive 3D porous composite scaffold from regenerated cellulose and cuttlebone-derived hydroxyapatite
}

Journal of Biomaterials Applications 2019, Vol. 33(6) 876-890 (C) The Author(s) 2018 Article reuse guidelines: sagepub.com/journals-permissions DOI: |0.1|77/08853282|88||040 journals.sagepub.com/home/jba @SAGE

\author{
Alisa Palaveniene', Sedef Tamburaci ${ }^{2}$, Ceren Kimna ${ }^{2}$ (D, \\ Kristina Glambaite', Odeta Baniukaitiene', \\ Funda Tihminlioğlu' ${ }^{2}$ and Jolanta Liesiene'
}

\begin{abstract}
Recently, usage of marine-derived materials in biomedical field has come into prominence due to their promising characteristics such as biocompatibility, low immunogenicity and wide accessibility. Among these marine sources, cuttlebone has been used as a valuable component with its trace elemental composition in traditional medicine. Recent studies have focused on the use of cuttlebone as a bioactive agent for tissue engineering applications. In this study, hydroxyapatite particles were obtained by hydrothermal synthesis of cuttlebone and incorporated to cellulose scaffolds to fabricate an osteoconductive composite scaffold for bone regeneration. Elemental analysis of raw cuttlebone material from different coastal zones and cuttlebone-derived $\mathrm{HAp}$ showed that various macro-, micro- and trace elements - $\mathrm{Ca}, \mathrm{P}, \mathrm{Na}, \mathrm{Mg}, \mathrm{Cu}, \mathrm{Sr}$, $\mathrm{Cl}, \mathrm{K}, \mathrm{S}, \mathrm{Br}, \mathrm{Fe}$ and $\mathrm{Zn}$ were found in a very similar amount. Moreover, biologically unfavorable heavy metals, such as $\mathrm{Ag}$, $\mathrm{Cd}, \mathrm{Pb}$ or $\mathrm{V}$, were not detected in any cuttlebone specimen. Carbonated hydroxyapatite particle was further synthesized from cuttlebone microparticles via hydrothermal treatment and used as a mineral filler for the preparation of cellulosebased composite scaffolds. Interconnected highly porous structure of the scaffolds was confirmed by micro-computed tomography. The mean pore size of the scaffolds was $510 \mu \mathrm{m}$ with a porosity of $85 \%$. The scaffolds were mechanically characterized with a compression test and cuttlebone-derived HAp incorporation enhanced the mechanical properties of cellulose scaffolds. In vitro cell culture studies indicated that MG-63 cells proliferated well on scaffolds. In addition, cuttlebone-derived hydroxyapatite significantly induced the ALP activity and osteocalcin secretion. Besides, HAp incorporation increased the surface mineralization which is the major step for bone tissue regeneration.
\end{abstract}

Keywords

Cuttlebone, bioinorganic elements, hydroxyapatite, osteoconductivity, bone tissue engineering

\section{Introduction}

Nowadays, the use of marine-derived materials in biomedical and pharmaceutical engineering has been reaching a previously unseen scale due to their high biocompatibility, biodegradability, non-toxicity, low immunogenicity, attractive cost and wide accessibility all over the world. ${ }^{1}$ These sources such as seashells, sea urchin, cuttlebone and coral are selectively used in tissue engineering and drug delivery systems due to their unique structure and bioactive elements. ${ }^{2,3}$

Development of polymer-based composite scaffolds with mineral filler usually improves the mechanical, morphological characteristics and supports osteoblast-like cells adhesion and proliferation on a graft surface. ${ }^{4}$ Among inorganic fillers, naturally derived sources can be preferred with their non-toxicity and high availability.

\footnotetext{
'Department of Polymer Chemistry and Technology, Kaunas University of Technology, Kaunas, Lithuania

${ }^{2}$ Department of Chemical Engineering, Izmir Institute of Technology, Izmir, Turkey

\section{Corresponding author:}

Funda Tihminlioğlu, Izmir Institute of Technology, Urla, Izmir 35430, Turkey.

Email: fundatihminlioglu@iyte.edu.tr
} 
The use of the cuttlebone as a natural filler in specific biomedical areas is possible by preserving the structure and composition of the cuttlebone or by modifying the original material.

Cuttlebone is an endoskeleton of marine mollusca Sepia and consists of principally Aragonite which is the crystallized form of $\mathrm{CaCO}_{3} \cdot{ }^{5}$ Cuttlebone is a cheap, easily available natural biomaterial showing similar chemical and crystal structure to coral. ${ }^{6}$

Cuttlebone has already been used for medical applications for many centuries in the traditional medicine of China and India. It was established as a valuable component of medicines for treating various diseases including dermatological, gastrological, gynecological, otorhinolaryngological and related health complaints. ${ }^{7,8}$ Nowadays, the use of cuttlebone for bone tissue engineering applications has come into prominence due its physical and chemical characteristics. Cuttlebone's lamellar matrix structure providing high porosity and ease of processability with its low cost makes it ideal candidate as bone substitute for bone tissue engineering applications. ${ }^{9}$

Hydroxyapatite (HAp) particles are extensively used in scaffolds since they are the main component of inorganic portion of the bone tissue. ${ }^{10}$ HAp particles serve as a calcium and phosphate source which is required for osteogenic differentiation. ${ }^{11}$ Synthesis of HAp from natural calcium carbonate sources, like cuttlebone, is very attractive for bone tissue engineering. Literature findings indicate that cuttlebone and cuttlebonederived HAp particles showed better biocompatibility when compared to synthetic Hap. ${ }^{5,12-16}$ Naturally derived HAp particles are characterised as nonstoichiometric HAp or carbonated HAp with biologically active trace elements, such as $\mathrm{Mg}, \mathrm{Sr}$ and $\mathrm{Na} .{ }^{17,18}$ The carbonated HAp particles have improved biocompatibility when compared to stoichiometrically pure HAp since they are chemically similar to natural human bone. ${ }^{19,20}$ In addition, it was indicated that the cuttlebone-derived HAp incorporation induced the mineralization of composite scaffolds. ${ }^{21} \mathrm{HAp}$ could be extracted or synthesized from natural calcium sources via alkaline hydrolysis, thermal calcination, hydrothermal or microwave syntheses, also using solgel or chemical precipitation methods. It was reported that the HAp maintained the microporous structure of the cuttlebone after hydrothermal conversion. ${ }^{9}$ Other applications of calcium HAp include injectable carboxymethylcellulose-based microspheres for vocal fold pathologies treatment, ${ }^{5}$ microparticles for antiwrinkle, facial rejuvenation treatment ${ }^{6}$ and HApbased synthetic orbital implants. ${ }^{7}$

The aim of this work was to analyze the elemental composition of cuttlebone specimens from different coastal zones and to prepare osteoconductive cellulose-based composite scaffold with cuttlebonederived hydroxyapatite (CB-HAp) filler for bone tissue engineering applications. The CB- HAp particles were obtained by hydrothermal synthesis from cuttlebone particles. The physical and chemical structure of cuttlebone-derived HAp was characterized with FTIR, XRD, SEM and XRF analyses. The morphology of the cuttlebone-derived HAp incorporated cellulose scaffolds was determined with SEM and Micro CT analyses. The mechanical properties of scaffolds were determined with compression test. The in vitro cytotoxicity, proliferation, alkaline phosphatase (ALP) activity and osteocalcin (OCN) secretion of MG-63 cells on composite scaffolds were investigated. The in vitro biomineralization on composite scaffolds was determined with EDX analysis, von Kossa and Alizarin Red stainings.

\section{Materials and methods}

\section{Materials}

Cuttlebone samples were purchased from Vital Pet Products Ltd (UK) and also collected manually from the seashores of Sohar (Sultanate of Oman) in 2013, Trapani (Italy) in 2015, Caldes d'Estrac (Spain) in 2016 and Pyra (Cyprus) in 2017. Ammonium dihydrogen phosphate (Merck) was used for hydrothermal synthesis. Cellulose acetate (Mn 50,000, Sigma-Aldrich) was used for scaffold preparation. Minimum essential medium (MEM, Sigma-Aldrich), fetal bovine serum (FBS-Lonza) penicillin-streptomycin solution and L-glutamine (Lonza) were used for cell culture studies. L-ascorbic acid and $\beta$-glycerophosphate (SigmaAldrich) were used for osteogenic medium preparation. Silver nitrate, sodium thiosulfate and Alizarin Red S (ARS) (Sigma- Aldrich) were used for von Kossa and ARS staining. Water-soluble tetrazolium (WST-1) ready to use cell proliferation reagent (BioVision Inc.), ALP-Enzyline PAL optimise kit (Biomerieux Inc.) were used for in vitro assays.

\section{Synthesis of HAp and characterization of cuttlebone materials}

Cuttlebone pieces (UK product) were crushed, milled using vibrating cup mill Pulverisette 9 (Fritsch GmbH, Germany) and sieved using sieve shaker Haver EML digital plus (Haver\&Boecker, Germany). The fraction of the particle size $<80 \mu \mathrm{m}$ was collected. Hydrothermal synthesis was performed by mixing cuttlebone microparticles and $\mathrm{NH}_{4} \mathrm{H}_{2} \mathrm{PO}_{4}$ suspended solution (1:0.6 molar ratio) for $2 \mathrm{~h}$. Cuttlebone powder was assigned as $\mathrm{CaCO}_{3}$, because cuttlebone consists of approximately $90 \%$ of $\mathrm{CaCO}_{3}$ in aragonite form. ${ }^{22}$ 
Amount of materials for the hydrothermal reaction was calculated to reach $\mathrm{Ca} / \mathrm{P}$ molar ratio 1.67 with regard to HAp. The reaction was carried out at nonstirred pressure vessel (PARR Instrument Company, USA), keeping the suspension inside a $50 \mathrm{~mL}$ PTFE vessel at $200^{\circ} \mathrm{C}$ temperature for $8 \mathrm{~h}, 100$ bar.

Fourier-transform infrared (FTIR) spectroscopy analysis was performed using an FTIR spectrometer (Perkin-Elmer, USA). The samples were prepared by mixing the finely powdered material with $\mathrm{KBr}$ in an agate mortar at a 1:50 ratio and pressing the mixture into homogeneous pellets. Mid-infrared spectral range data, corresponding to $4000-400 \mathrm{~cm}^{-1}$, was used; the resolution was $4 \mathrm{~cm}^{-1}$.

X-ray diffractometer (Bruker AXS, Germany) was used for X-ray powder diffraction (XRD) analysis. The morphology of samples was observed by scanning electron microscopy (SEM, FEI Quanta 200 FEG) technique. The elemental composition was evaluated by X-ray fluorescence (XRF) spectrometric analysis using Bruker X-ray S8 Tiger WD (Bruker AXS $\mathrm{GmbH}$, Germany) and the Spectra ${ }^{\text {plus }}$ quantexpress method.

\section{Preparation of $3 D$ cellulose-based scaffold with CB-HAp}

A cellulose gel was prepared as described previous1y. ${ }^{23,24}$ Briefly, CB-HAp powder (7 g) was mechanically mixed with $150 \mathrm{~mL}$ of cellulose gel for $30 \mathrm{~min}$. The porous structure of the scaffolds was achieved using the freeze-drying technique (Christ Alpha 2-4 LSC freeze-dryer, Germany). Cylindrical samples of approx. $1.0 \mathrm{~cm}$ in height and $1.5 \mathrm{~cm}$ in diameter were prepared. Regenerated cellulose/CB-HAp sample was assigned as RC/CB-HAp scaffold and regenerated cellulose (RC) scaffold was used as a control group.

\section{Characterization of the scaffolds}

Morphology. Morphometric parameters of RC/CB-HAp scaffold were characterized by micro-computed tomography ( $\mu \mathrm{CT}$, Scanco Medical AG, Switzerland) system. Morphometric parameters of the scaffolds were defined using "general scientific" terms instead of terms for bone samples.

Percent object volume (Object volume/total volume: Obj.V/TV), specific surface (Obj.S/Obj.V) and structure thickness (St.Th), used to refer to percent bone volume $(B V / T V)$, specific surface of bone $(B S / B V)$ and trabecular thickness (Tr.Th), respectively, were computed from $3 \mathrm{D}$ images. The porosity and pore sizes of the scaffolds were determined directly from twodimensional (2D) images. Structure separation (St.Sp) and structure linear density (St.Li.Dn) parameters, used to refer to trabecular separation (Tr.Sp) and trabecular number $(T b . N)$, respectively, were calculated from the primary indices ${ }^{25}$

$$
S t . S p=2(T V-O b j . V) / O b j . S
$$

where TV is a total VOI (volume of interest) volume, $\mathrm{mm}^{3}$; Obj.V is an object volume, $\mathrm{mm}^{3}$; and Obj.S is an object surface area, $\mathrm{mm}^{2}$.

$$
\text { St.Li.Dn }=0.5 \mathrm{Obj} . \mathrm{S} / \mathrm{TV}
$$

Mechanical properties. Mechanical properties of CBHAp reinforced scaffolds were determined with compression test in dry and wet conditions according to the ASTM5024-95a standard. Compression test was performed under $50 \mathrm{kgf}$ loading with $5 \mathrm{~mm} / \mathrm{min}$ rate. Scaffolds were compressed up to $75 \%$ strain. In wet condition, scaffolds were hydrated with PBS solution to observe their structure and mechanical endurance in body condition.

\section{In vitro cell culture studies}

Scaffolds were sterilized with $70 \%$ ethanol solution before in vitro tests. The human osteosarcoma MG63 cell line was used as osteoblast model for in vitro studies.

In vitro cytotoxicity. The in vitro cytotoxicity was evaluated by WST-1 assay for 24, 48 and 72-h incubation periods. Indirect extraction method was used according to the ISO-10993 standard. The cell viability was investigated by interacting the cell monolayer with the extraction medium of scaffolds. Extraction medium was prepared by incubating sterilized scaffolds in MEM at $37^{\circ} \mathrm{C}$ for $24 \mathrm{~h}$. MG-63 cells were seeded on 96-well plates with a density of $10^{5}$ cells $/ \mathrm{mL}$ and extraction medium was used as an incubation medium for 72 h. Cells incubated with cell culture medium (MEM) were used as negative control group. The cytotoxicity of the scaffolds was measured spectrophotometrically at $440 \mathrm{~nm}$ for $24 \mathrm{~h}, 48 \mathrm{~h}$ and $72 \mathrm{~h}$. The cell viability \% is calculated as

$$
\text { Cell viability } \%=\frac{\text { Absorbance of sample }}{\text { Absorbance of NC }} \times 100
$$

where NC is the negative control.

Cell proliferation assay. MG-63 cells with a density of $2.5 \times 10^{6}$ cells/scaffold were seeded on scaffold surface with $20 \mu \mathrm{l}$ inoculation volume. Then, scaffolds were 
incubated for $4 \mathrm{~h}$ at $37^{\circ} \mathrm{C}$ to provide cell attachment. After $4 \mathrm{~h}$, the culture medium was added subsequently, and scaffolds were incubated at $37^{\circ} \mathrm{C}$, humidified with $5 \% \mathrm{CO}_{2}$ atmosphere. The cell culture medium was refreshed twice a week. Cell proliferation was evaluated with WST-1 Cell Viability Kit (BioVision Inc.) and the absorbance of supernatants was measured at $440 \mathrm{~nm}$.

ALP activity. ALP is an important osteoblastic isoenzyme for the determination of early osteogenic differentiation. Therefore, ALP activity was detected for 7, 14 and 21 days of incubation. MG-63 cells were seeded on scaffolds at a density of $2.5 \times 10^{6}$ cell/scaffold and cultivated with osteogenic medium. The medium was refreshed twice a week. The absorbance of the medium was measured by a plate reader (Varioskan Flash) at $405 \mathrm{~nm}$ to detect the extracellular ALP activity.

OCN determination with ELISA. OCN production of MG63 cells incubated on scaffolds was measured using Sandwich-ELISA assay (Human OC/BGP (Osteocalcin) ELISA Kit, Elabscience). The culture media extracted from scaffolds were analyzed for 21 and 28 days of incubation periods.

In vitro biomineralization of MG-63 cells on cellulose-HAp scaffold. Biomineralization is a process in which release of biomolecules controls the nucleation and growth of minerals such as carbonates and phosphates. ${ }^{26}$ It is a key step in bone tissue formation with the accumulation of calcium and phosphate minerals. Thus, MG-63 cells incubated on scaffolds for 14 days and analyzed with SEM to observe biomineralization on scaffold surface. Samples were coated with a thin gold layer under Argon gas by using Emitech K550X before the analysis. SEM analysis was performed with Quanta FEG 250 (at $7 \times 10^{-2} \mathrm{mbar}$ and $15 \mathrm{~mA}$ ). The analysis was performed with backscatter mode to investigate the biomineralization. $\mathrm{Ca}$ and $\mathrm{P}$ minerals accumulated on scaffold surface were evaluated by EDX analysis.

Mineral formation by cells on scaffolds surface was qualitatively detected with von Kossa and ARS stainings. Scaffolds incubated in osteogenic medium for 21 days were washed with $1 \times$ PBS solution thrice and treated with $3.7 \%$ paraformaldehyde for fixation. Calcium deposition was determined by von Kossa staining indirectly with the observation of phosphatebonded calcium minerals. Therefore, ARS staining is used with von Kossa which directly detects calcium mineral formation. Scaffolds were treated with $1 \%$ $(w / v)$ aqueous silver nitrate solution under UV light for 30 min for von Kossa staining. The solution was removed, and scaffolds were washed with distilled water. Finally, scaffolds were incubated with $5 \%(\mathrm{w} /$ v) sodium thiosulfate solution to remove unreacted silver. Filtered $2 \%(\mathrm{w} / \mathrm{v})$ aqueous ARS solution $(\mathrm{pH}=4.1)$ was used for ARS staining procedure. Scaffolds were incubated with the ARS solution for $30 \mathrm{~min}$ in the dark and washed with distilled water several times. Stained samples were observed under stereomicroscope (SOIF DA 0737). Semi-quantitative analysis of calcium deposition on scaffolds was investigated by ARS extraction method. Extraction media were measured spectrophotometrically at $405 \mathrm{~nm}$ to determine the calcium deposition differences.

\section{Statistical analysis}

All the data were reported as mean with standard error of three replicates. Analyses were evaluated with twoway analysis of variance (ANOVA) and the significance $(P<0.05)$ was determined by GraphPad-Prism6.

\section{Results}

\section{Characteristics of cuttlebone material}

Trace elements in cuttlebone of different coastal regions were detected by XRF technique, which is generally assumed as a precise sophisticated analytical tool for the evaluation of elemental composition of materials. Macro- and microelements, such as $\mathrm{Ca}, \mathrm{P}, \mathrm{Mg}, \mathrm{Sr}$, $\mathrm{Fe}, \mathrm{Na}, \mathrm{Cl}, \mathrm{S}, \mathrm{K}, \mathrm{Cu}$ and $\mathrm{Br}$, were determined in cuttlebone samples (Table 1). The lamellar and dorsal cuttlebone layers featured similar elemental compositions. Elemental composition of human bone ${ }^{27}$ and CB-HAp (this study) was given for comparison. The amount of phosphorus in prepared CB-HAp was found as $12 \%$ which is almost the same as in human bone (15\%).

According to data on the elemental composition of cuttlebone specimens from different coastal areas, trace elements, such as $\mathrm{Si}(0.02 \pm 0.005), \mathrm{P}(0.13 \pm 0.03), \mathrm{Mg}$ $(0.21 \pm 0.04), \mathrm{S}(0.22 \pm 0.1), \mathrm{Sr}(0.46 \pm 0.06)$ and $\mathrm{Na}$ $(0.89 \pm 0.24)$, occurred in very similar amounts. Only the concentration of chlorine varied approx. within $0.04-2.31 \%$ for different specimens. Most of these elements are essential for the proper bone metabolic processes and wound injury regeneration. Trace amounts of $\mathrm{Cu}, \mathrm{Zn}$ or $\mathrm{Fe}$ that were found in cuttlebone specimens are also beneficial for metabolic processes in a living organism. Moreover, biologically unfavorable heavy metals, such as $\mathrm{Ag}, \mathrm{Cd}, \mathrm{Pb}$ or $\mathrm{V}$, were not detected in any specimen. XRF analysis data revealed the presence of trace elements in cuttlebone-derived $\mathrm{HAp}$, such as $\mathrm{Sr}, \mathrm{Mg}, \mathrm{Si}, \mathrm{S}$, and Fe. These trace elements could positively influence the enzymatic activity of the bone, as well as cartilage formation and collagen synthesis in vivo. ${ }^{28}$ 
Table I. Elemental composition (\%) of human bone, cuttlebone specimens from different coastal zones and cuttlebone-derived hydroxyapatite.

\begin{tabular}{|c|c|c|c|c|c|c|c|}
\hline \multirow[b]{2}{*}{ Element } & \multirow[b]{2}{*}{ Human bone $e^{25}$} & \multicolumn{5}{|c|}{ Cuttlebone } & \multirow[b]{2}{*}{ CB-HAp } \\
\hline & & UK & $\begin{array}{l}\text { Sohar, } \\
\text { Sultanate } \\
\text { of Oman }\end{array}$ & $\begin{array}{l}\text { Trapani, } \\
\text { Italy }\end{array}$ & $\begin{array}{l}\text { C. d'Estrac, } \\
\text { Spain }\end{array}$ & $\begin{array}{l}\text { Pyra, } \\
\text { Cyprus }\end{array}$ & \\
\hline Calcium & 34.8 & 47.36 & 53.9 & 55.5 & 53.1 & 51.4 & $48.3 \pm 0.4$ \\
\hline Phosphorus & 15.2 & 0.07 & 0.12 & 0.15 & 0.15 & 0.15 & $11.9 \pm 1.2$ \\
\hline Sodium & 0.90 & 0.51 & 0.86 & 0.94 & 1.13 & 1.03 & - \\
\hline Magnesium & 0.72 & 0.16 & 0.19 & 0.25 & 0.21 & 0.26 & $0.15 \pm 0.07$ \\
\hline Silicon & - & - & 0.03 & 0.02 & 0.02 & 0.02 & $0.02 \pm 0.01$ \\
\hline Copper & & 0.0003 & 0.0023 & 0.0043 & 0.005 & - & $0.004 I \pm 0.00007$ \\
\hline Fluoride & 0.03 & - & - & - & - & & - \\
\hline Strontium & - & 0.42 & 0.46 & 0.53 & 0.50 & 0.39 & $0.47 \pm 0.01$ \\
\hline Chlorine & 0.13 & 1.62 & 1.87 & 0.04 & 2.31 & 2.25 & - \\
\hline Potassium & 0.03 & 0.05 & 0.05 & 0.01 & 0.07 & 0.08 & \\
\hline Sulphur & - & 0.33 & 0.21 & 0.05 & 0.25 & 0.25 & $0.0062 \pm 0.0008$ \\
\hline Iron & & 0.01 & 0.01 & 0.0067 & - & - & $0.02 \pm 0.01$ \\
\hline Bromine & & 0.0071 & 0.0106 & - & 0.0134 & 0.02 & - \\
\hline Zinc & 0.0126 & 0.07 & 0.05 & 0.0079 & 0.09 & 0.06 & $0.0036 \pm 0.0024$ \\
\hline
\end{tabular}
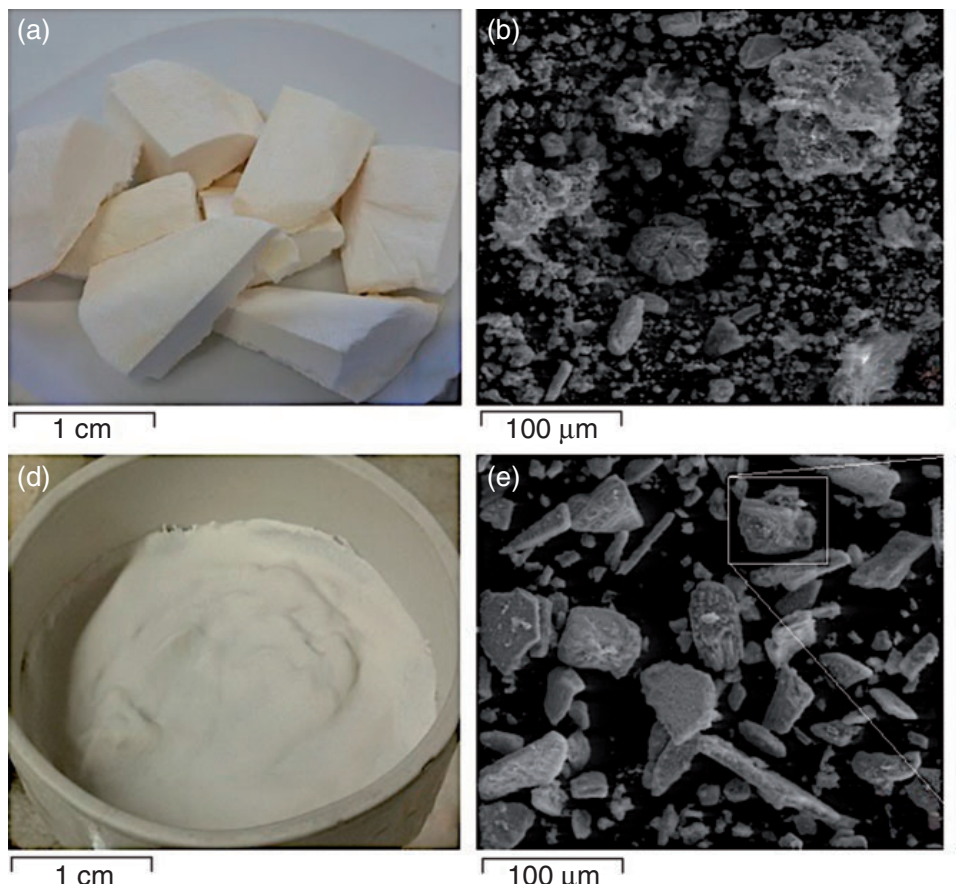

$100 \mu \mathrm{m}$
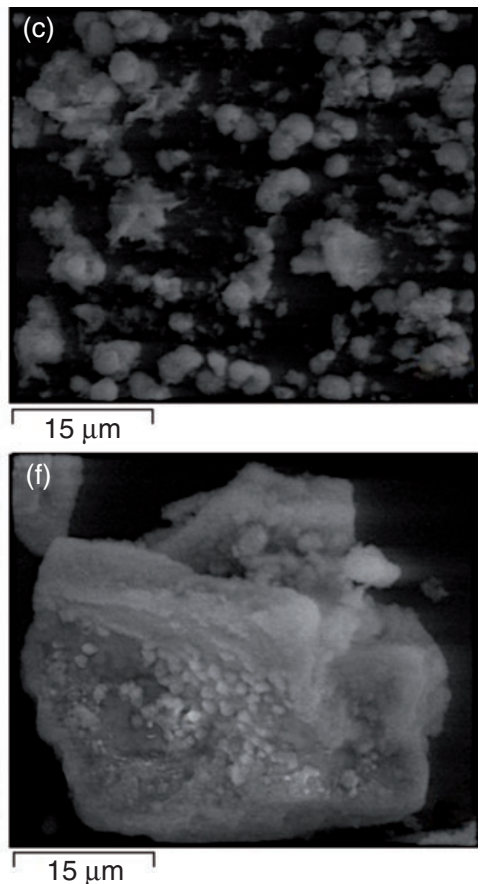

Figure I. Cuttlebone-derived materials: cuttlebone pieces (a); microphotographs of cuttlebone powder (b, c); cuttlebone powder after hydrothermal treatment using 0.6 M (NH4)2HPO4 solution (d); microphotographs of CB-HAp particles (e, f).

CB-HAp was synthesized via hydrothermal reaction from cuttlebone microparticles (Figure 1(a) to (d)), used as a source of calcium carbonate (equation (4))

$$
\begin{aligned}
10 \mathrm{CaCO}_{3} & +6\left(\mathrm{NH}_{4}\right)_{2} \mathrm{HPO}_{4} \rightarrow \mathrm{Ca}_{10}\left(\mathrm{PO}_{4}\right)_{6}(\mathrm{OH})_{2} \\
& +\mathrm{H}_{2} \mathrm{O}+\mathrm{CO}_{2} \uparrow
\end{aligned}
$$

The obtained results show that the $\mathrm{Ca} / \mathrm{P}$ ratio in cuttlebone and cuttlebone-derived HAp was 197.4 and 4.05 , respectively. The calcium and phosphorus ratio in the human bone and in cuttlebone-derived HAp is similar: 2.29 and 4.05, respectively. Cuttlebone powder particles less than $100 \mu \mathrm{m}$ in diameter were ready to agglomerate, probably because of 
(a)

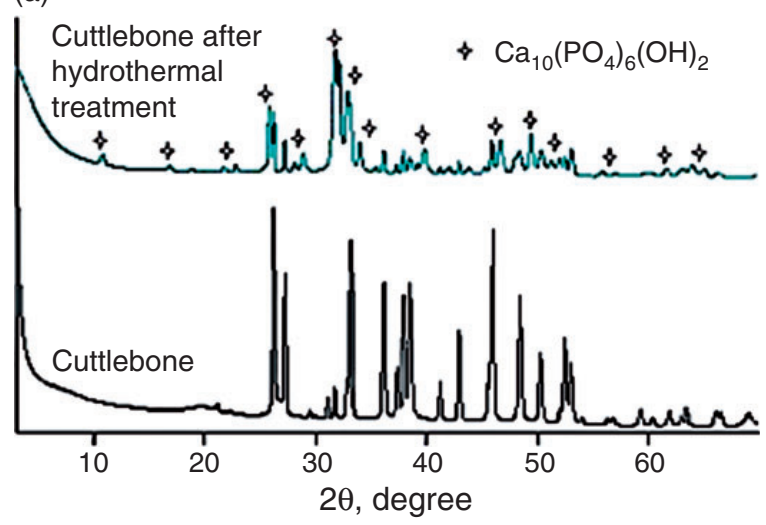

(b)

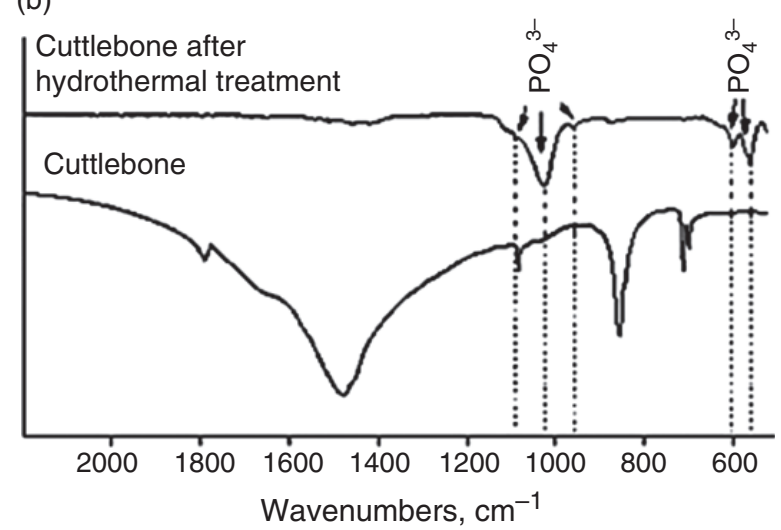

Figure 2. XRD patterns (a) and FTIR spectra (b) of cuttlebone and cuttlebone after hydrothermal treatment.

the hygroscopic nature of chitin which is present in the structure of cuttlebone. ${ }^{22}$ A microsphere shape of the material $(\sim 1-2 \mu \mathrm{m}$ size $)$ which is typical of HAp occurred after hydrothermal synthesis ${ }^{29}$ (Figure 1(e) and (f)).

The X-ray diffraction pattern of cuttlebone powder shows characteristic peaks of aragonite at $26^{\circ}, 33^{\circ}$ and $45^{\circ}$ (Figure 2(a)). Peaks of low intensity at $10^{\circ}-25^{\circ}$ could be attributed to $\beta$-chitin. ${ }^{22,30}$ The conversion of cuttlebone powder into HAp after hydrothermal synthesis by treatment with $\left(\mathrm{NH}_{4}\right)_{2} \mathrm{HPO}_{4}$ was analyzed by using XRD and compared to the XRD pattern of untreated cuttlebone. The XRD pattern of the material after hydrothermal synthesis shows characteristic peaks of HAp according to the powder diffraction file No. 01-089-4405 for HAp at $10.7^{\circ}, 22.8^{\circ}, 25.7^{\circ}, 28.0^{\circ}$, $32.1^{\circ}, 34.0^{\circ}, 39.7^{\circ}, 46.6^{\circ}, 49.4^{\circ}, 56.9^{\circ}, 63.1^{\circ}$ and $64.9^{\circ}$. The main indices characteristic to HAp are presented in this pattern. Some characteristic peaks of aragonite are also present in this pattern, but the intensities are low compared with the peaks of untreated cuttlebone powder. The XRD data confirmed that the product obtained via hydrothermal synthesis of cuttlebone particles consisted of $81 \%$ HAp and $19 \%$ aragonite.

FTIR spectra showed the characteristic absorption peaks assigned to aragonite at $1077 \mathrm{~cm}^{-1}$ for $\nu_{1}$, a doublet at $713 \mathrm{~cm}^{-1}$ and $700 \mathrm{~cm}^{-1}$ for $\nu_{4}$ and $856 \mathrm{~cm}^{-1}$ for $\nu_{2}$ (Figure 2(b)). With regard to carbonate ions, the peaks at $1790 \mathrm{~cm}^{-1}$ for $\nu_{2}$ and $2519 \mathrm{~cm}^{-1}$ and $1481 \mathrm{~cm}^{-1}$ for $\nu_{3}$ are also visible. A broad absorption band in the $3650-3200 \mathrm{~cm}^{-1}$ range was assigned to the stretching vibration of $\mathrm{O}-\mathrm{H}$ groups. A weak absorption peak at $1630 \mathrm{~cm}^{-1}$ was attributed to amide groups thus confirming the presence of chitin..$^{22,26,31}$ The vibrational frequencies of $\mathrm{C}-\mathrm{O}-\mathrm{C}$ at the $\beta$-glucoside linkage were observed at $1164 \mathrm{~cm}^{-1}$ and $895 \mathrm{~cm}^{-1} .32$ The absorption peaks of the $\mathrm{PO}_{4}{ }^{3-}$ group at $565 \mathrm{~cm}^{-1}$,
$606 \mathrm{~cm}^{-1}, 960 \mathrm{~cm}^{-1}, 1029 \mathrm{~cm}^{-1}$ and $1090 \mathrm{~cm}^{-1}$ were observed in the FTIR spectrum of cuttlebone after hydrothermal treatment. Only very low absorption peaks of aragonite are visible in the spectrum of cuttlebone powder after hydrothermal synthesis. The presence of absorption peaks of the phosphate group in FTIR spectra and XRD characteristic peaks confirmed the formation of HAp from cuttlebone microparticles.

\section{Cellulose-based scaffolds with CB-HAp}

CB-HAp microparticles were used for the preparation of the cellulose-based scaffolds (RC/CB-HAp). Structure and morphometric parameters of RC scaffold were used for comparison.

RC/CB-HAp composite scaffolds had more compact structure than that of the RC scaffold because of the formation of smaller pores (Figure 3(a)). The addition of CB-HAp microparticles had an influence on the reduction of the mean pore size of the scaffold (RC/CB-HAp): $750 \mu \mathrm{m}$ and $510 \mu \mathrm{m}$ for RC scaffold and $\mathrm{RC} / \mathrm{CB}$-Hap scaffold, respectively. The porosity of the composite scaffold was determined by the distinct pore size distribution (Figure 3(b)). It was found that high percentage of the pores in the RC/CB-HAp scaffold was in $300-700 \mu \mathrm{m}$ range $(67 \%$ of all the pore volume). The percentage of pores in $10-100 \mu \mathrm{m}$ and $>800 \mu \mathrm{m}$ was negligible. No pores larger than 1000 $\mu \mathrm{m}$ were observed in the RC/CB-HAp scaffold structure.

Morphometric indices of the scaffolds were evaluated using $\mu \mathrm{CT}$ scanning. The obtained data were compared with bone parameters at different trabecular regions (Table 2). Immobilizing CB-HAp microparticles into the RC gel increased porosity of the framework compared with RC scaffold

Specific surface (Obj.S/Obj.V) value of the RC/CBHAp composite was two times larger compared with 
(a)

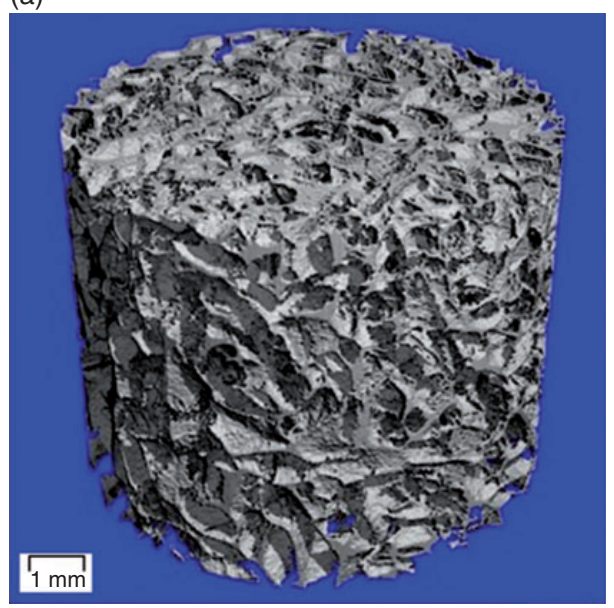

(b)

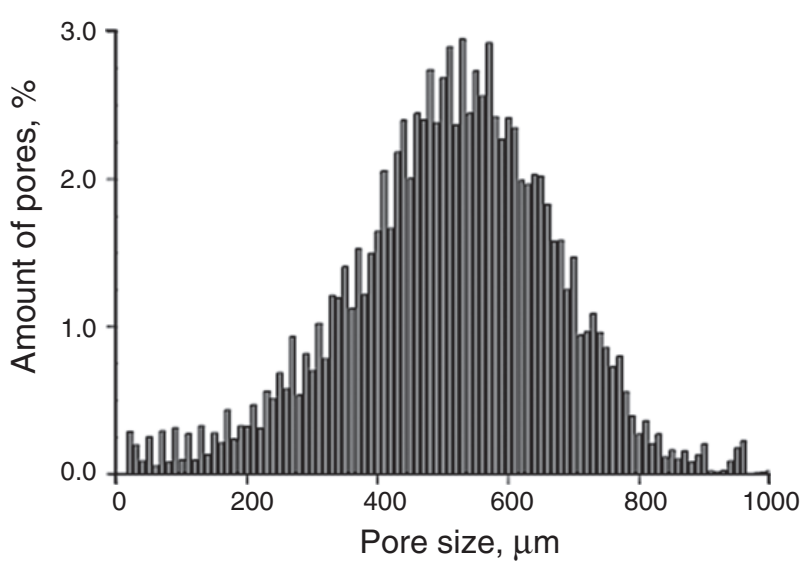

Figure 3. Morphology of the RC/CB-HAp scaffold: $3 \mathrm{D}$ image, evaluated by $\mu \mathrm{CT}$ (a); pore size distribution within the scaffold (b).

Table 2. Morphometric indices of the scaffolds and descriptive statistics of some parameters of human trabecular bone.

\begin{tabular}{|c|c|c|c|c|c|}
\hline \multirow[b]{2}{*}{ Morphometric indices } & \multicolumn{5}{|c|}{ Scaffold or bone region } \\
\hline & RC/CB-HAp & $\mathrm{RC}$ & $\begin{array}{l}\text { 5th vertebral } \\
\text { body }^{33}\end{array}$ & $\begin{array}{l}\text { Ultra-distal } \\
\text { radius }^{34}\end{array}$ & $\begin{array}{l}\text { Mandibular } \\
\text { condyle }^{35}\end{array}$ \\
\hline Obj.V/TV, \% & 14.10 & 24.87 & 22.95 & 23.00 & - \\
\hline Obj.S/Obj.V, mm $\mathrm{m}^{-1}$ & 33.37 & 14.50 & - & - & - \\
\hline St.Th, mm & 0.09 & 0.21 & 0.10 & 0.10 & $0.11-0.22$ \\
\hline St.Sp, mm & 0.36 & 0.42 & 0.31 & 0.34 & $0.56-0.85$ \\
\hline St.Li.Dn, $\mathrm{mm}^{-1}$ & 2.36 & 1.80 & 2.20 & 2.40 & $1.16-1.67$ \\
\hline Mean pore size, $\mu \mathrm{m}$ & 510 & 750 & - & - & - \\
\hline Porosity, \% & 85.9 & 75.0 & - & - & $72.6-87.4$ \\
\hline
\end{tabular}

Obj.V/TV: percent object volume; Obj.S/Obj.V: specific surface; St.Th: structure thickness; St.Sp: structure separation; St.Li.Dn: structure linear density.

RC scaffold. Figure 4 depicts a detailed $2 \mathrm{D}$ view of the internal structure of the RC/CB-HAp scaffold. The porous structure with interconnected pores could be observed from the cross-section view of the scaffolds.

The shape of pores is non-symmetric and randomly ordered; pores connect with each other by structuring pervious canals. This fact argues in favour of rapid angiogenesis, as well as acceleration of scaffold mineralization.

\section{Mechanical characterization}

Compression test results of RC and RC/CB-HAp scaffolds are depicted in Figure 5(a) and (b). CB-Hapreinforced scaffolds showed higher mechanical strength and endured higher stress at dry condition. Compression modulus of control $(0.0496 \mathrm{MPa})$ and Hap- $(0.048 \mathrm{MPa})$ incorporated scaffolds were similar to each other. In wet conditions, higher mechanical strength and compression modulus were observed on the RC/CB-HAp scaffolds. Hydrated scaffolds showed more elastic behavior compared to dry scaffolds.

\section{In vitro cytotoxicity}

In vitro cytotoxicity results indicated that $\mathrm{RC} / \mathrm{CB}-\mathrm{HAp}$ scaffold showed slightly lower cell viability compared to RC scaffold (Figure 6(a)). Cell viability result of RC/ CB-HAp was found to be statistically significant in comparison to $\mathrm{RC}$ at 48 and $72 \mathrm{~h}$. The cell viability range after $72 \mathrm{~h}$ of incubation varied between 55 and $67 \%$ indicating that the scaffolds are non-toxic to MG63 cells.

\section{Cell proliferation}

MG-63 cells successfully proliferated on CB-HAp incorporated scaffolds for 14 days of incubation with a gradual increase observed during 3, 7, 10 and 14 days of incubation (Figure 6(b)). However, significant 

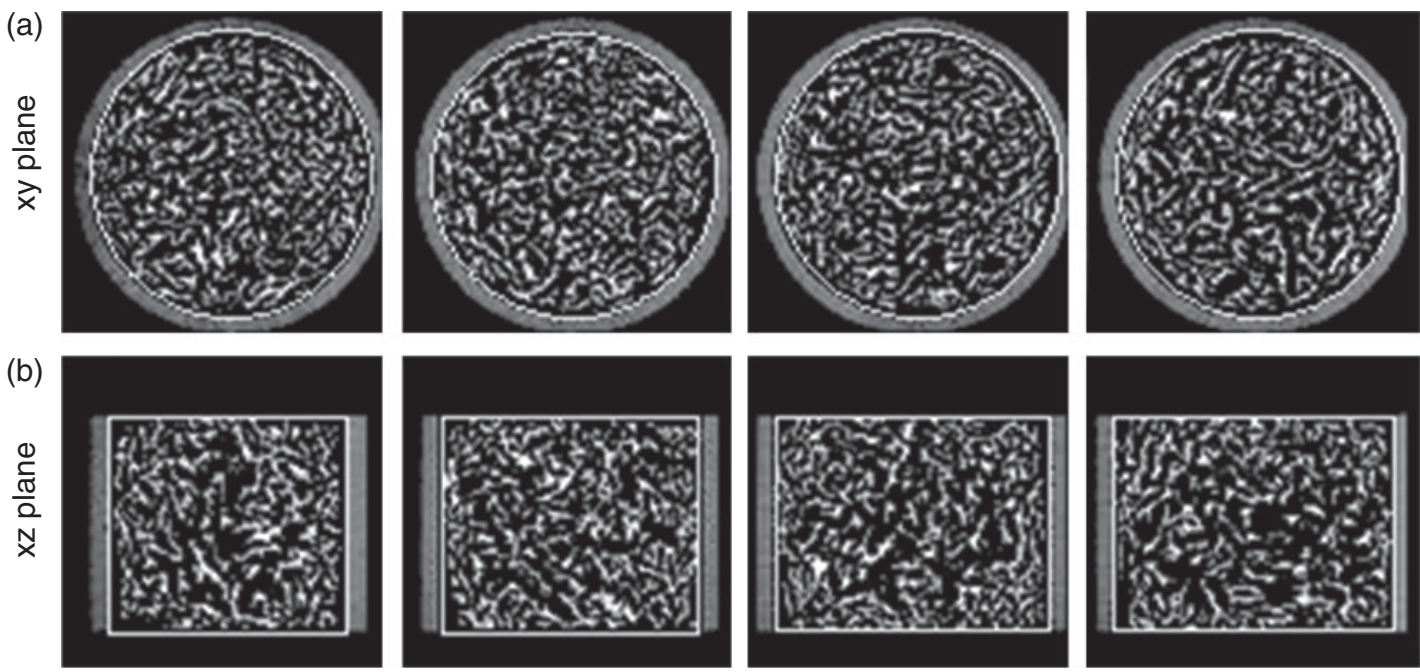

Figure 4. 2D overview images of RC/CB-HAp scaffold: $x y$ plane (a); xz plane (b).
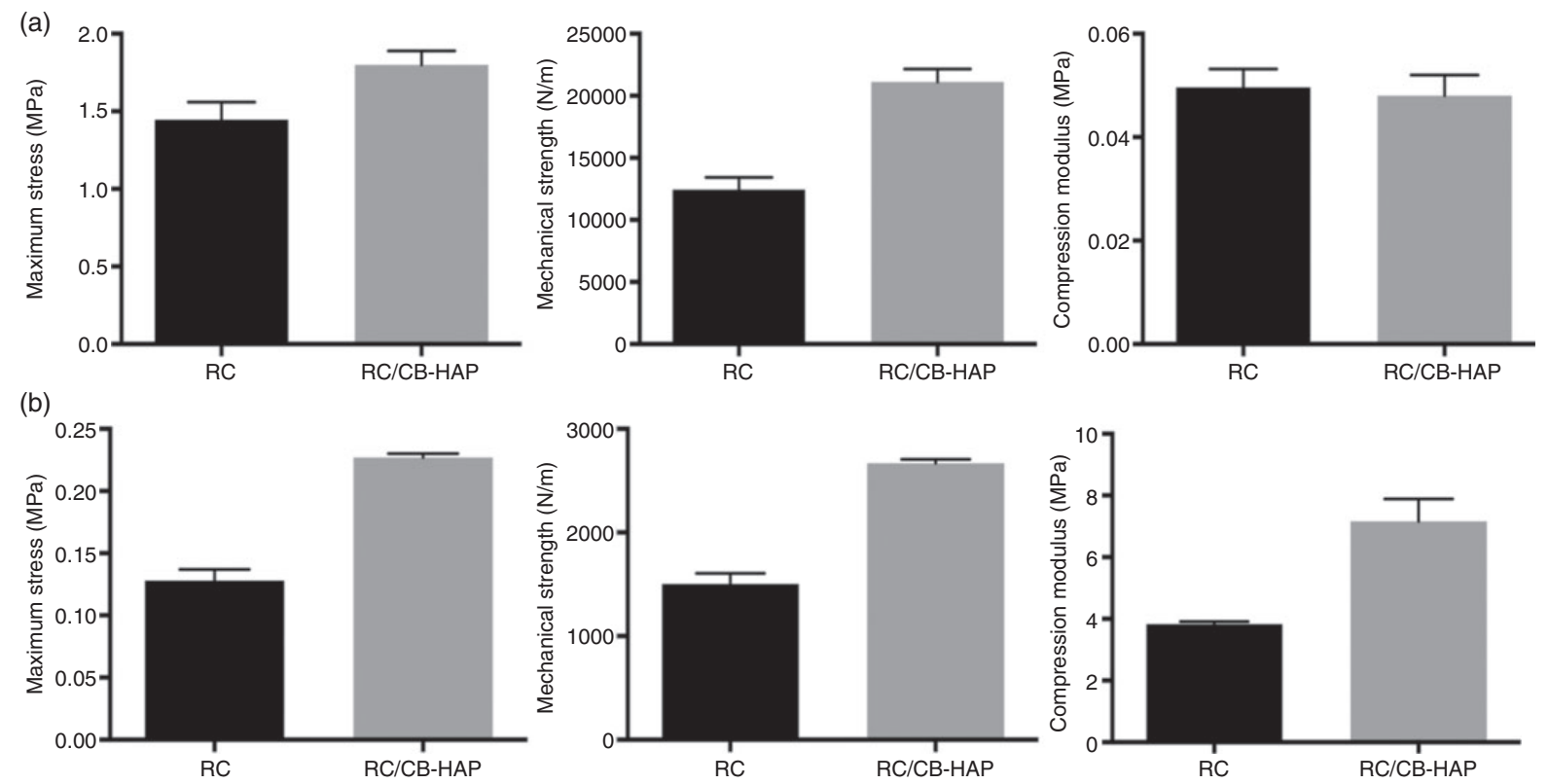

Figure 5. Maximum stress, mechanical strength and compression modulus of scaffolds in dry (a) and wet condition (b).

increase in MG-63 proliferation was observed at 7th and 14th day.

\section{ALP activity}

ALP activity of MG-63 cells was evaluated with the colorimetric ALP activity assay for 7, 14 and 21 days. The ALP activity difference between groups in all incubation periods was found statistically significant. During the incubation period, MG-63 cells expressed slightly increasing ALP activity on control group, whereas significant increase in ALP activity was observed for RC/CB-HAp scaffolds with incubation time (Figure 7).

\section{OCN secretion}

Figure 8 shows the osteocalcin (OC) production of MG-63 cells on RC and RC-CB/HAp scaffolds for 14 and 21 days. Results indicated that OC secretion of MG-63 cells was found to be significantly higher on HAp incorporated RC-CB scaffolds for 21 day of incubation. 
(a)

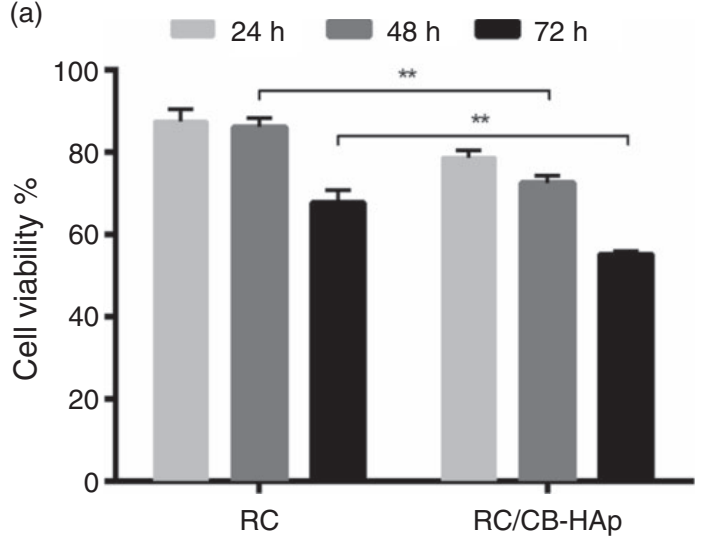

(b)

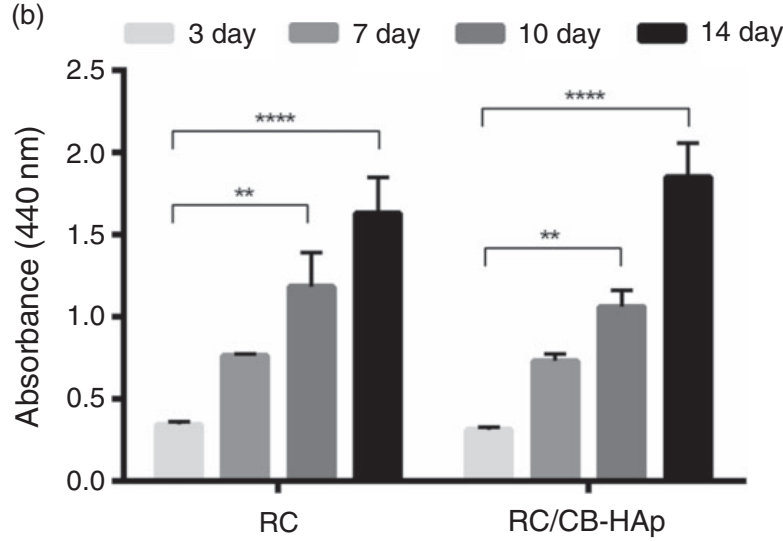

Figure 6. Cell viability \% of MG-63 cells incubated with scaffold extracts for 24 h, 48 h, and 72 h (a); MG-63 proliferation on scaffolds for the $3,7,10$ and 14 days of incubation periods (b).

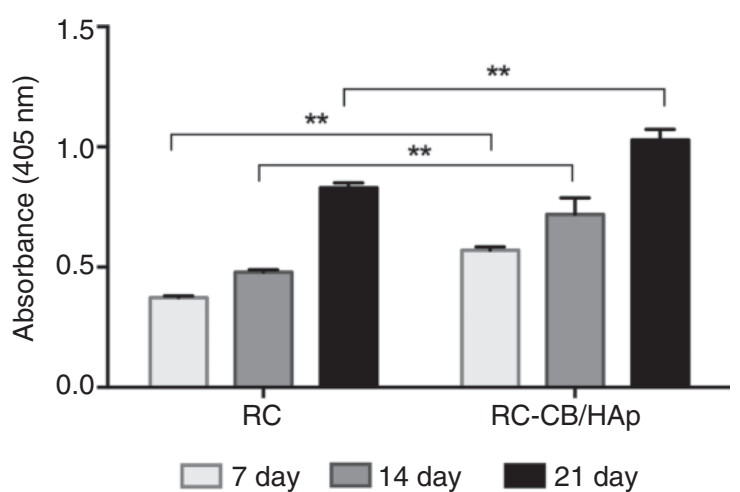

Figure 7. ALP activity of MG-63 cells cultured on scaffolds for 7,14 and 21 days.

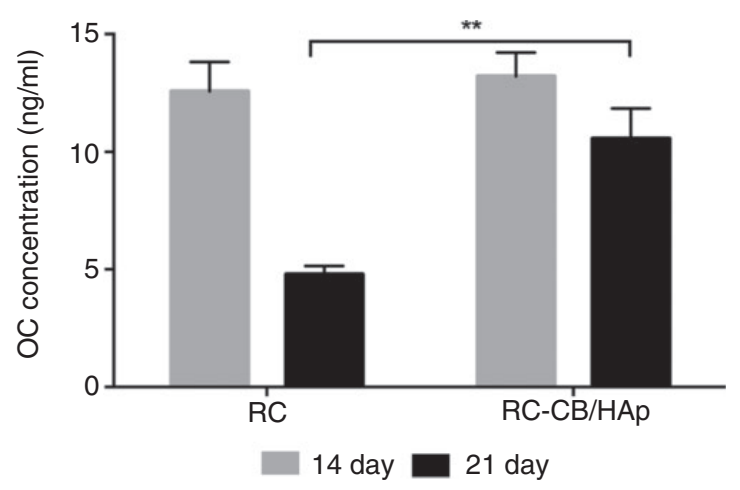

Figure 8. Osteocalcin production of MG-63 cells on RC and RC-CB/Hap scaffolds for 14 and 21 days incubation periods.

\section{In vitro biomineralization of MG-63 cells on scaffold}

According to SEM images, the RC/CB-HAp scaffolds showed enhanced mineral coating when compared to RC scaffolds (Figure 9). In addition, EDX mapping results of $\mathrm{RC} / \mathrm{CB}-\mathrm{HAp}$ scaffolds indicated that $\mathrm{Ca}$ and $\mathrm{P}$ ion accumulation was significantly higher than RC scaffolds (Figure 10).

According to the stereoimages, significantly higher calcium and phosphate depositions were observed on the HAp-reinforced RC scaffolds when it is compared to $\mathrm{RC}$ control group. Von Kossa staining demonstrated high phosphate accumulation on RC/CB-HAp scaffolds, whereas the control group showed trace amount of brown stain on the peripheral region of the scaffold (Figure 11). In addition, ARS staining images showed higher calcium accumulation on RC/CB-HAp scaffolds, while calcium mineral deposition was not observed on RC construct (Figure 12). Semiquantification of ARS staining implied that HAp incorporation significantly induced the calcium deposition on scaffolds $(P<0.05)$ (Figure 13).

\section{Discussion}

\section{Bioactivity potential of cuttlebone filler}

The safety of marine-derived materials is generally related to the anthropogenic contaminants. Growing urban development could negatively affect the coastal environment, and also marine-derived materials, that could be used for biomedical applications. Herein, data on possible occurrence/accumulation of heavy metals in cuttlefish bone are presented; and its relation to the safety aspects of cuttlebone is discussed.

The changeable elemental composition of naturally derived materials is generally assumed as a drawback compared with analogous synthesized materials. However, the results of our study showed that variation of elements in cuttlebone material from different coastal zones was marginal. According to data, trace elements, such as $\mathrm{Si}, \mathrm{P}, \mathrm{Mg}, \mathrm{S}, \mathrm{Sr}$ and $\mathrm{Na}$, occurred in very similar amounts. Only concentration of chlorine 
(a)

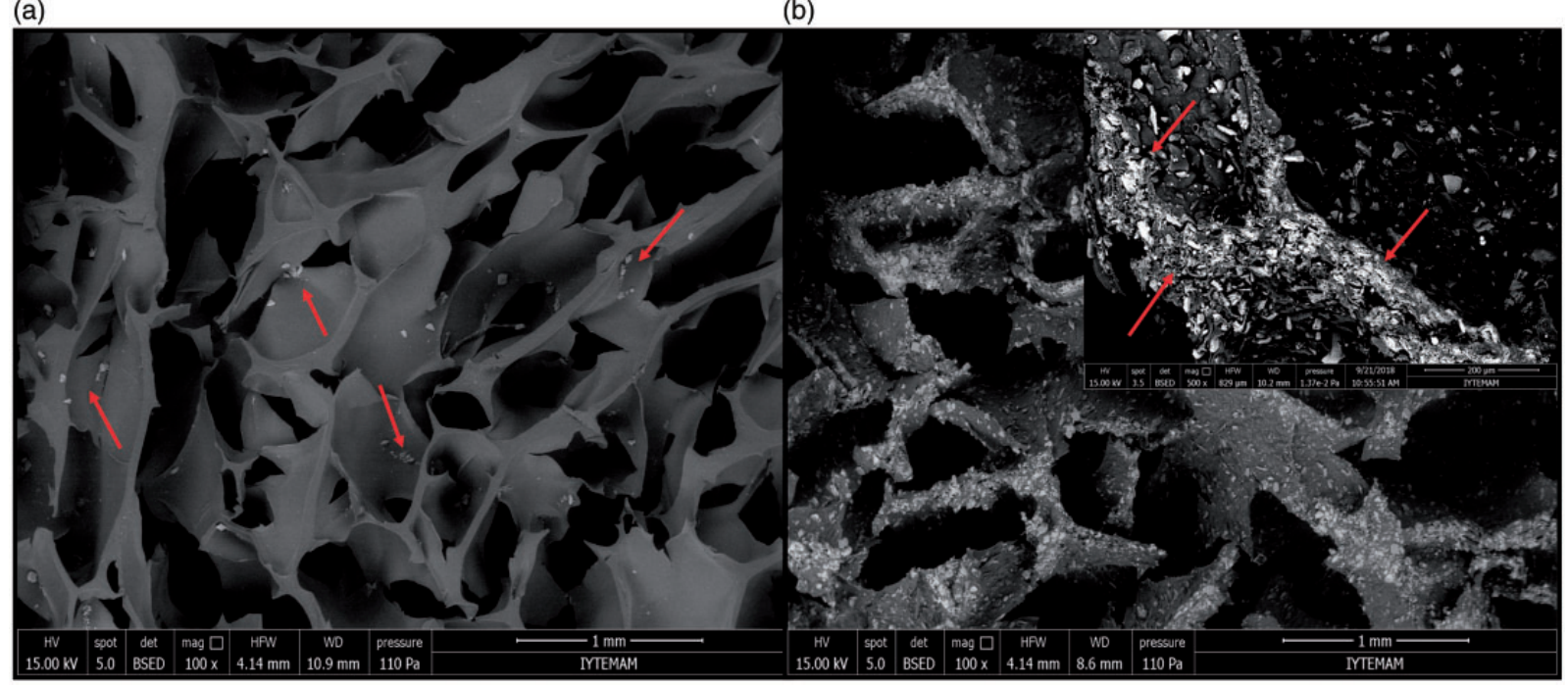

Figure 9. Biomineralization on the surface of RC (a) and RC/CB-HAp (b) scaffolds for 14th day.

Ca Ko1
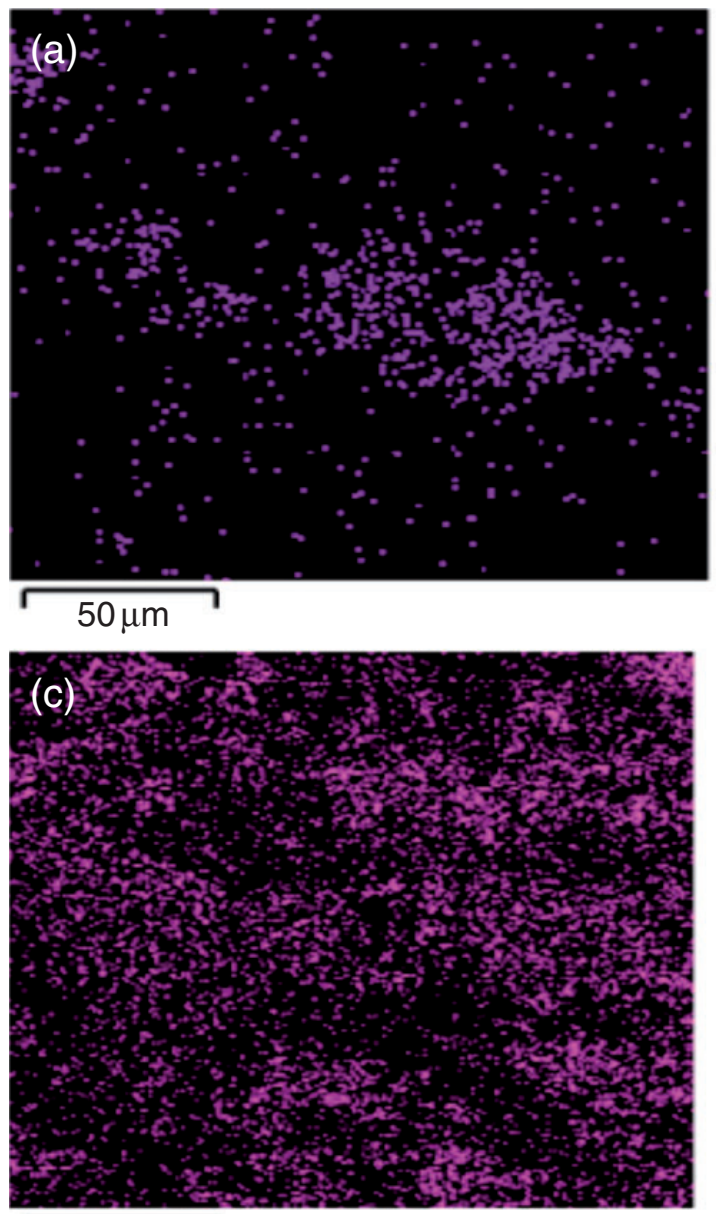

$50 \mu \mathrm{m}$
P Ko1
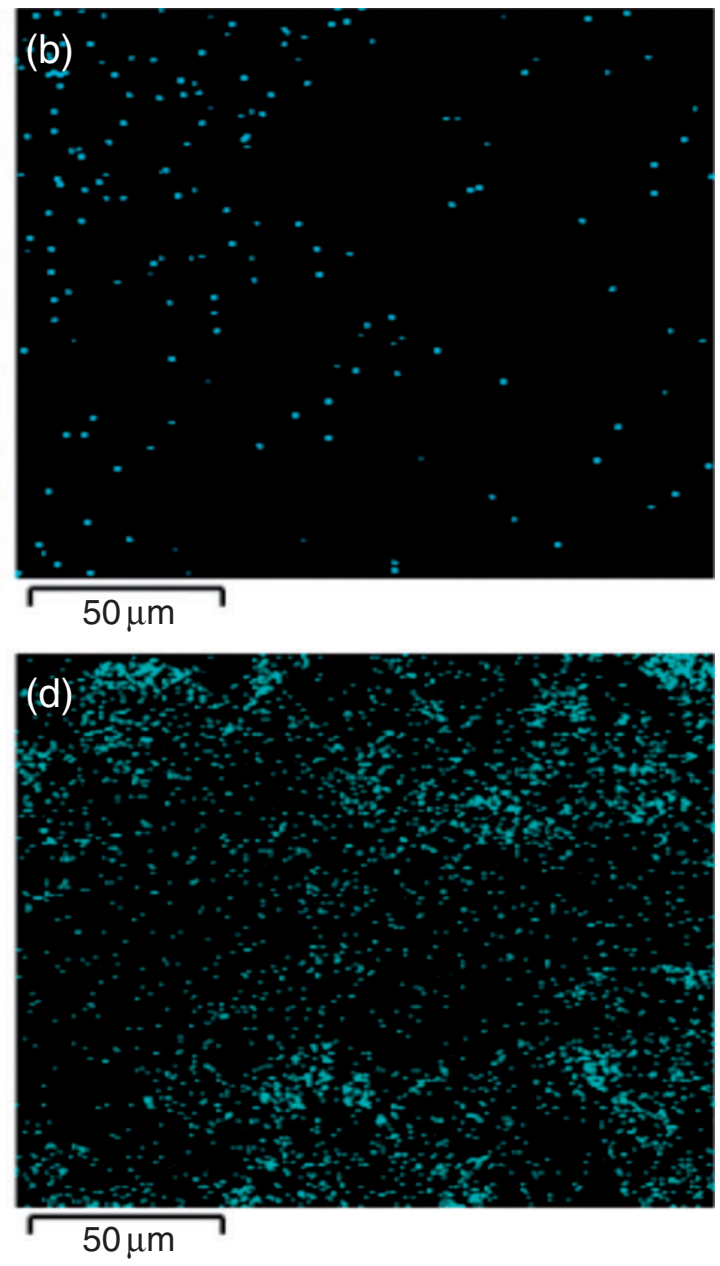

Figure 10. Elemental analysis of RC and RC/CB-HAp scaffolds for 14th day: $C a(a, c), P(b, d)$ mapping with EDX analysis. 

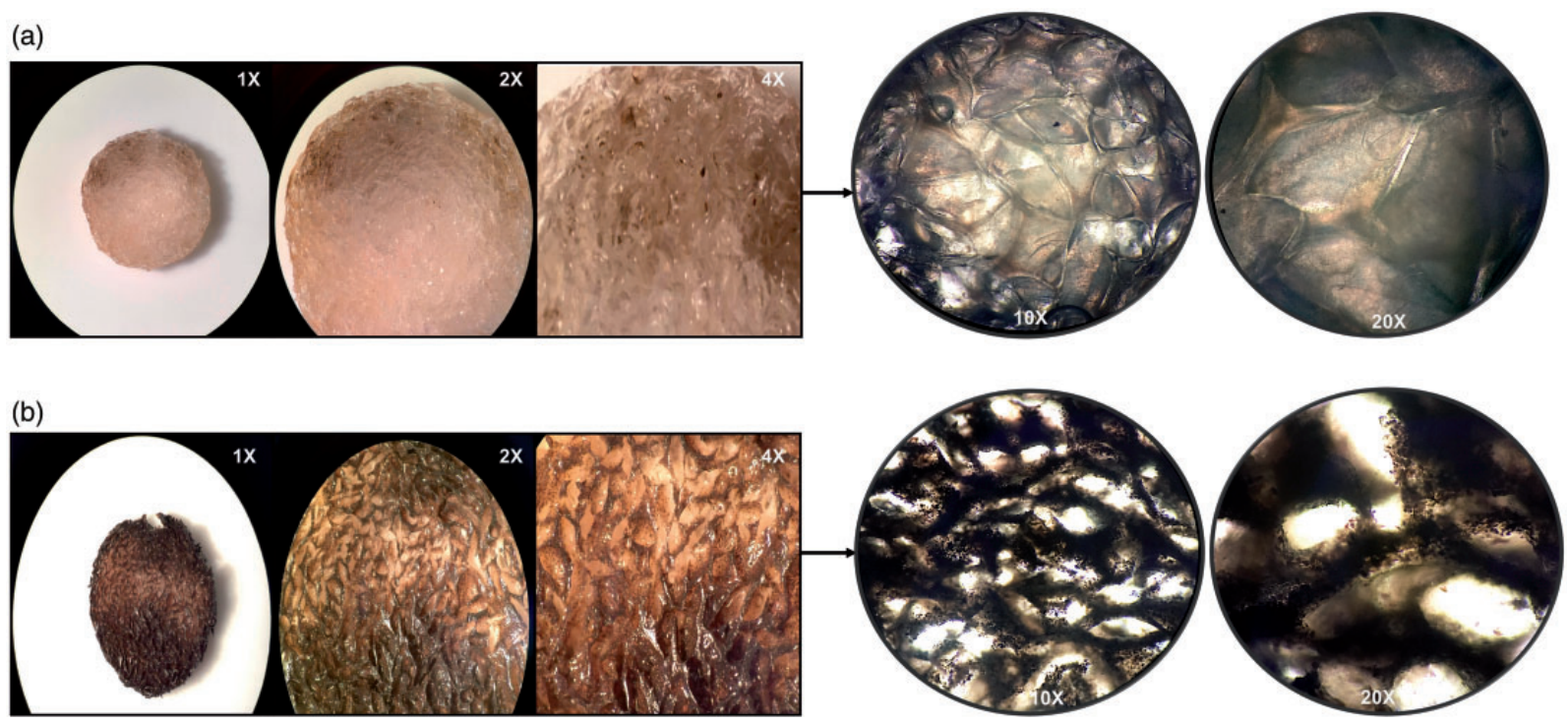

Figure I I. von Kossa staining of RC (a) and RC/CB-HAp (b) scaffolds, respectively.

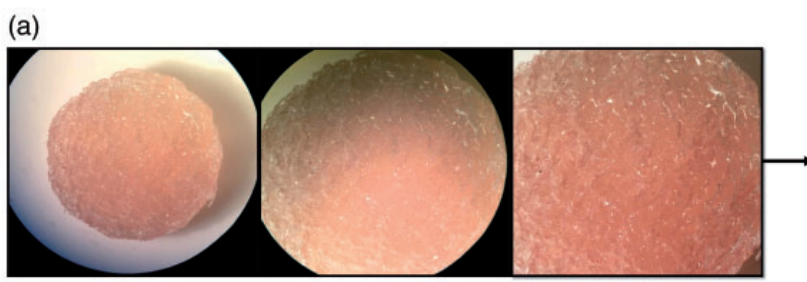

(b)
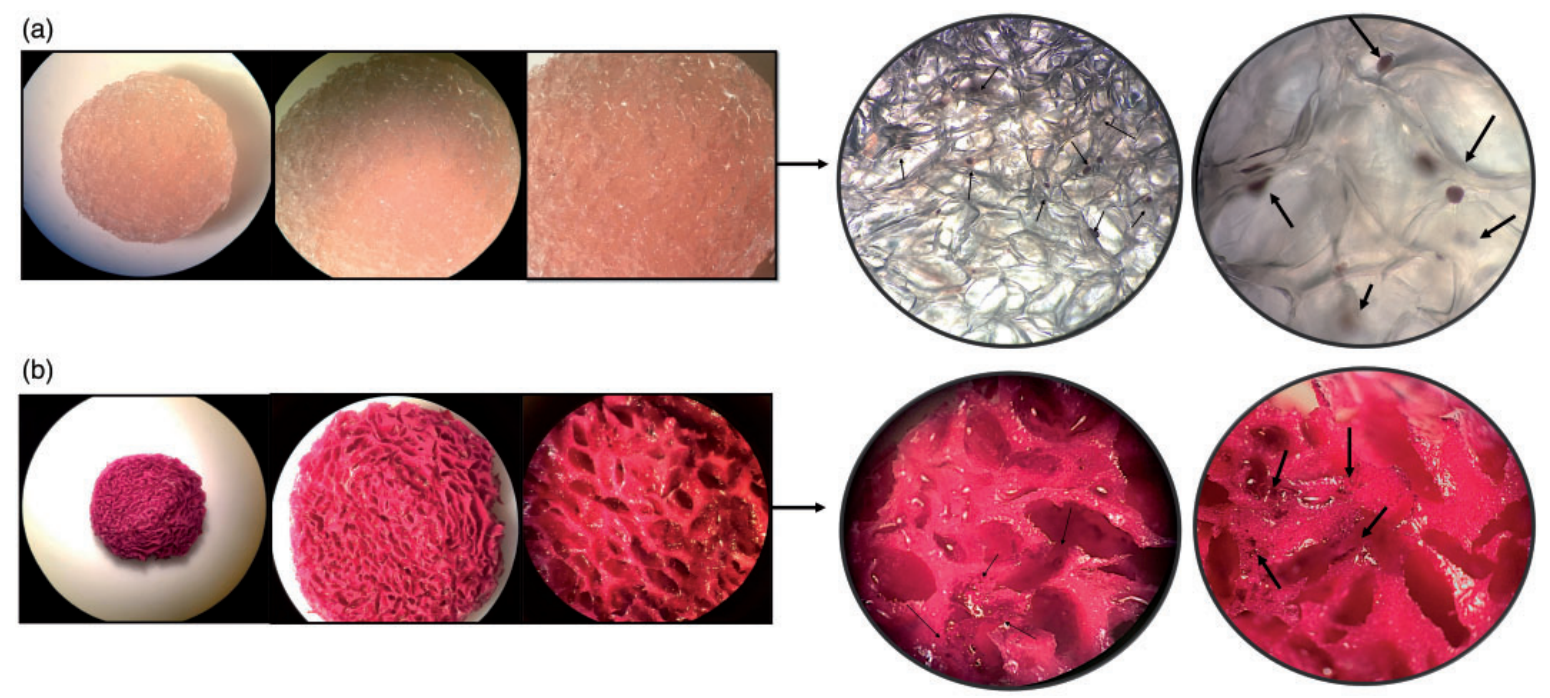

Figure I2. Alizarin Red S (ARS) staining of RC (a) and RC/CB-HAp (b) scaffolds, respectively.

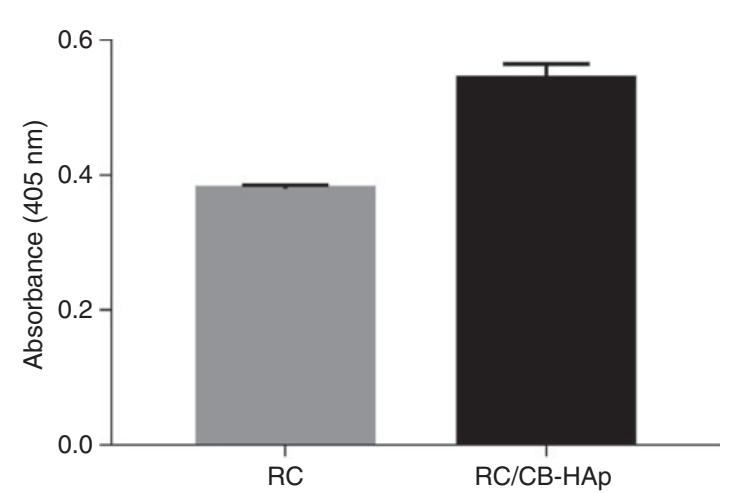

Figure 13. Semi-quantification of calcium deposition on scaffolds for 21 days of incubation. varied within $0.04-2.31 \%$ for specimens of different origin. Most of these elements are essential for proper bone metabolic processes and wound injury regeneration. Trace amounts of $\mathrm{Cu}, \mathrm{Zn}$ or $\mathrm{Fe}$ that were found in cuttlebone specimen are also beneficial for metabolic processes in the living organism. ${ }^{36}$

Miramand et al. ${ }^{37}$ determined variation of heavy metal concentrations in Sepia officinalis by atomic absorption spectrophotometry. It was found that digestive gland of cuttlefish serves as a major organ for heavy metal storage during the life cycle of a cuttlefish. Generally, the concentrations of heavy metals in cuttlebones, such as $\mathrm{Ag}, \mathrm{Cd}, \mathrm{Pb}$ and $\mathrm{V}$, were close to the detection limit and remarkably lower compared to a 
whole-body mass. In their study, Farraj et al. ${ }^{38}$ determined the concentrations of $\mathrm{Zn}, \mathrm{Cu}, \mathrm{Pb}, \mathrm{Ni}, \mathrm{Cr}$ and $\mathrm{Cd}$ in a mantle of cuttlefish Sepia pharaonis. The authors highlighted the fact that the levels of heavy metals in cuttlefish mantle showed no risk for the customers because were lower/agreeable than the Maximum Permissible Levels established by various authorities and organizations. Additionally, the authors postulated that a digestive gland and edible parts (mantle and arms) are targeted parts of a cuttlefish body for heavy metals, such as $\mathrm{Pb}, \mathrm{Ni}$ and $\mathrm{Cd}$, accumulation. Oppositely, the presence of $\mathrm{Zn}, \mathrm{Cu}$ and $\mathrm{Cr}$ in cuttlefish organs is essential for homeostasis of physiological functions within the lifecycle of an animal. For example, zinc is an important trace element for any living organisms, because it is a structural component of proteins, positively affecting a number of protein functions. The presence of copper is related to a protein hemocyanin, which is essential for the respiration of cuttlefish. Chromium is generally known as an essential trace element for glucose tolerance. It needs to be emphasized that acceptable doses of $\mathrm{Zn}, \mathrm{Cu}, \mathrm{Cr}$ and $\mathrm{V}$ are rather beneficial, and not untoward, in the treatment of various diseases and conditions. ${ }^{39,40}$ Moreover, biologically unfavorable heavy metals, such as $\mathrm{Ag}, \mathrm{Cd}$, $\mathrm{Pb}$ or $\mathrm{V}$ were not detected in any specimen.

In bone tissue engineering, numerous studies described the attempts to enhance bioactivity and osteoconductivity of synthetic stoichiometric HAp by introducing various biologically active ions. ${ }^{41-43}$ The bioactivity of cuttlebone-derived HAp (CB-HAp) and synthetic HAp granules was compared. ${ }^{12}$ It was found that after seven days the cells cultured on CB-HAp granules had almost 2-fold higher ALP activity compared to their activity on synthetic HAp granules. The results indicate that there is higher biocompatibility of CB-HAp comparing with a synthetic compound.

Bone homeostasis is mostly related to a quantitative expression, particular ratios and specific properties of the inorganic fraction. Trace elements also influence the enzymatic activity of bone, as well as cartilage formation and collagen synthesis. ${ }^{44}$ Moreover, food supplements with minerals are well-established for improving health disorders, such as bone trauma, hypertensive disease, diabetes mellitus, post-operative periods, etc. The list of trace minerals beneficial for human health includes, but is not limited to $\mathrm{B}, \mathrm{Cr}$, $\mathrm{Mo}, \mathrm{Se}, \mathrm{V}, \mathrm{Co}, \mathrm{Zn}, \mathrm{Cu}$ and $\mathrm{Fe} .{ }^{45-48}$ To summarize, inorganic elements of cuttlebone are all considered to be valuable from biomedical and pharmaceutical perspective.

Carbonated HAp or other substituted HAp is beneficial for bone scaffold design, because this bioactive material possesses better mechanical strength than pure Hap. ${ }^{49}$ Moreover, biologically active trace elements were observed in the composition of CB-HAp. Strontium, magnesium, silicon, sulphur, iron and zinc were found in a CB-HAp. These trace elements could positively influence the enzymatic activity of bone, bone formation and regeneration processes, as well as cartilage formation and collagen synthesis in vivo. ${ }^{44}$ As could be noticed, calcium and phosphorus concentrations are actually the same in human bone and CBHAp composition (Table 1). Strontium is usually presented in a composition of human bone. It is also the main component in drugs for osteoporosis, because it stimulates bone formation. ${ }^{50}$ To sum up, nonstoichiometric carbonated HAp with nature-adjusted bioactive elements was synthesized from cuttlebone microparticles. The material could therefore be used for development of composite scaffolds or as a final bone grafting material.

The multi-scale range of pores in RC/CB-HAp scaffolds more likely mimics the structure of natural bone (Figure 3(b)). Porosity values (\%) of the RC/CB-HAp scaffold correlated well with the values of trabecular bone values at different sites (Table 2). Additionally, larger SS/SV value that was observed for $\mathrm{RC} / \mathrm{CB}-\mathrm{HAp}$ scaffold, should more likely facilitate cell adhesion, proliferation and differentiation. ${ }^{51,52}$

\section{Mechanical characterization}

The mechanical properties of the prepared scaffolds were tested in both dry and wet conditions. In dry conditions, the compression modulus of the dry RC and $\mathrm{RC} / \mathrm{CB}-\mathrm{HAp}$ scaffolds were close to each other. Dry scaffolds did not show an elastic behavior while they were compressed (Figure 5). In literature, numerous studies indicated that HAp reinforcement increased the mechanical properties of scaffolds. ${ }^{49,50}$ Similarly, in this study, the increase in maximum stress, mechanical strength and the compression modulus was observed with HAp incorporation. Incorporation of HAp into $\mathrm{RC}$ enhanced the mechanical strength from $1503.2 \mathrm{~N} /$ $\mathrm{m}$ to $2668.3 \mathrm{~N} / \mathrm{m}$ (\% 78 increase) and compression modulus from 3.8 $\mathrm{MPa}$ to $7.2 \mathrm{MPa}$ (\%89 increase) in wet conditions.

\section{In vitro studies}

The in vitro cytotoxicity assay was performed to determine the possible cytotoxic effect of scaffolds to MG63 cell line. The decrement in $72 \mathrm{~h}$ occurred but the viability of all groups was higher than $50 \%$. The cell proliferation assay was performed to observe the effect of HAp incorporation to RC scaffolds on MG-63 cell line (Figure 6). Recently, the effect of ion-doped HAp particles on the biological activity of biomaterials has been studied and it was observed that bivalent $\mathrm{Mg}$, 
$\mathrm{Zn}$ and Si ions improved the biocompatibility of HAp and supported the osteogenic differentiation of cells. ${ }^{53-}$ ${ }^{55}$ In this study, these trace elements were detected in cuttlebone-derived HAp particles and enhanced the bioactivity via inducing biomineralization on the surface. Our results indicated that MG-63 cells proliferated well on the CB-HAp incorporated RC scaffolds and showed a similar trend for both groups at 10 days of incubation. A significant increase in proliferation was seen for RC/CB-HAp scaffolds after 10 days. Similarly, Liuyun et al. ${ }^{56}$ investigated in vitro cell proliferation on nano-Hap-incorporated chitosan/carboxymethylcellulose scaffolds and showed that scaffolds provided good biocompatibility with MG-63 cell line. In another study, Tao et al. ${ }^{57}$ investigated the effect of HAp particles transformed from cuttlebone on marrow stromal osteoblast proliferation and indicated that cells proliferated well on the HAp particles. At the initial stages of mineralization process, ALP is the marker enzyme that controls the osteoblast differentiation by regulating the formation of inorganic phosphate. After the beginning of mineralization process, enzyme levels do not increase, and the mineralized matrix formation occurs with the HAp crystal formation. ${ }^{58}$ ALP activity results showed that CB-Hap incorporation induced the ALP activity of MG-63 cells on scaffolds and in good agreement with in vitro biomineralization study results (Figure 7).

OC is an important marker for osteoblast differentiation and initiates the biomineralization in bone regeneration. MG-63 is used as an appropriate model cell line for studying the OCN secretion. ${ }^{59}$ Therefore, in this study, OC secretion of MG-63 cells on scaffolds was investigated with sandwich ELISA assay. At an early period of biomineralization (14th day), similar OC concentrations were obtained for scaffolds. Results showed that HAp incorporation enhanced the OC production of MG-63 cells. OC secretion on RC/ CB-HAp scaffolds was found significantly higher than the control group (RC scaffold) at 21 days of incubation. SEM analysis was used to observe the mineral deposition on surface qualitatively. SEM images indicated that HAp incorporation increased the mineral formation on scaffold surface effectively at the early stage of incubation (Figure 9). In addition, EDX analysis was performed to detect the calcium and phosphate deposition on the surface that is important for the HAp nucleation in biomineralization process. SEM images showed that carbonated HAp incorporation prominently affected the biomineralization of MG-63 cells on scaffold surface by inducing mineral formation on the material surface. Elemental analysis results demonstrated that scaffolds include elements such as $\mathrm{C}$ and $\mathrm{O}$, derived from the cellulosic structure, while $\mathrm{Ca}$ and $\mathrm{P}$ resulted from biomineralization of MG-63 cells on scaffold surface (Figure 10). In a study, it was concluded that HAp incorporation supported the mineral nucleation on PCL scaffolds. ${ }^{60}$ Since HAp is the main mineral present in the composite structure of bone, it was concluded that RC/CB-HAp scaffolds provided a convenient microenvironment for biomineralization. Von Kossa and ARS studies were performed to observe phosphate and calcium deposition of MG-63 cells on scaffold surface incubated with osteogenic medium. The significant difference in groups was observed due to the enhanced biomineralization of RC/CB-HAp scaffolds (Figures 11 and 12). In a study, ARS staining was performed to observe the effect of HAp incorporation in collagen/chitosan fibers and it was revealed that HAp particles enhanced the calcium deposition on scaffolds. ${ }^{61}$ Therefore, the von Kossa and ARS staining indicated that the biomineralization significantly increased with the HAp incorporation into the matrix, which supported the SEM and EDX results (Figure 13).

\section{Conclusion}

In-depth elemental analysis of cuttlebone revealed that various bioinorganic elements were typical for cuttlebone from different coastal zones. However, any biologically unfavorable heavy metals, such as $\mathrm{Ag}, \mathrm{Cd}, \mathrm{Pb}$ or $\mathrm{V}$, were not detected. In this study, cuttlebone microparticles were used as a starting material for preparation of osteoconductive porous scaffold from regenerated cellulose and CB-HAp. Incorporation of CB-HAp enhanced the mechanical properties of cellulose scaffolds in both dry and wet conditions. Trace elements such as $\mathrm{Mg}$, $\mathrm{Si}$ and $\mathrm{Zn}$ found in the cuttlebone composition induced the biological activity of HAp particles. In vitro studies showed that CB-HAp particles did not show any cytotoxic effect on MG-63 cell lines. Cells successfully proliferated on $\mathrm{RC} / \mathrm{CB}$ HAp scaffolds and these results supported the cytocompatibility of fabricated scaffolds. Besides, incorporation of CB-HAp significantly increased the calcium/ phosphate deposition and induced the biomineralization process which is the major step for bone tissue regeneration.

\section{Acknowledgements}

The authors are thankful to İzmir Institute of Technology, Centre for Materials Research (IZTECH CMR) for SEM and stereomicroscopy imaging. Authors are grateful to Department of Silicate Technology (Kaunas University of Technology) for technical support. Authors are also grateful to Dr. Armandas Rumšas (Kaunas University of Technology, publishing office "Technologija") for English proofreading. 


\section{Declaration of Conflicting Interests}

The author(s) declared no potential conflicts of interest with respect to the research, authorship, and/or publication of this article.

\section{Funding}

The author(s) received no financial support for the research, authorship and/or publication of this article.

\section{ORCID iD}

Ceren Kimna (D) http://orcid.org/0000-0003-2283-4295

\section{References}

1. Monzack EL, et al. Natural Materials in Tissue Engineering Applications. In: Burdick J.A., Mauck R. L. (eds) Biomaterials for Tissue Engineering Applications. Springer, Vienna, 2011.

2. Ozyegin LS, et al. An alternative synthesis method for Di calcium phosphate (monetite) powders from mediterranean mussel (mytilus galloprovincialis) shells. J Aust Ceram Soc 2013; 49: 122-128.

3. Macha IJ, et al. Marine structure derived calcium phosphate-polymer biocomposites for local antibiotic delivery. Mar Drugs 2015; 13: 666-680.

4. Kane RJ, et al. Hydroxyapatite reinforced collagen scaffolds with improved architecture and mechanical properties. Acta Biomater 2015; 17: 16-25.

5. Sarin P, et al. Porous biphasic calcium phosphate scaffolds from cuttlefish bone. J Am Ceram Soc 2011; 94: 2362-2370.

6. Manoli F and Dalas E. Calcium carbonate crystallization on xiphoid of the cuttlefish. J Crystal Growth 2000; 217: 422-428.

7. Zhao Z, Liang Z and Ping G. Macroscopic identification of Chinese medicinal materials: traditional experiences and modern understanding. J Ethnopharmacol 2011; 134: 556-564.

8. Fang W, et al. Chinese herbal decoction as a complementary therapy for atrophic gastritis: a systematic review and meta-analysis. Afr J Tradit Complement Altern Med 2017; 14: 297-319.

9. Zhang $X$ and Vecchio KS. Conversion of natural marine skeletons as scaffolds for bone tissue engineering. Front Mater Sci 2013; 7: 103-117.

10. Tang X-J, Gui L and Lü X-Y. Hard tissue compatibility of natural hydroxyapatite/chitosan composite. Biomed Mater 2008; 3: 044115.

11. Sachlos E, Gotora D and Czernuszka JT. Collagen scaffolds reinforced with biomimetic composite nano-sized carbonate-substituted hydroxyapatite crystals and shaped by rapid prototyping to contain internal microchannels. Tissue Eng 2006; 12: 2479-2487.

12. Kim B-S, et al. Comparison of in vitro and in vivo bioactivity: cuttlefish-bone-derived hydroxyapatite and synthetic hydroxyapatite granules as a bone graft substitute. Biomed Mater 2014; 9: 025004.
13. Battistella E, et al. Transformed cuttlefish bone scaffolds for bone tissue engineering. Adv Mater Res 2010; 89: 47-52.

14. Kim BS, et al. Cellular attachment and osteoblast differentiation of mesenchymal stem cells on natural cuttlefish bone. J Biomed Mater Res 2012; 100: 1673-1679. no.

15. Milovac D, et al. PCL-coated hydroxyapatite scaffold derived from cuttlefish bone: in vitro cell culture studies. Mater Sci Eng C 2014; 42: 264-272.

16. Kim BS, et al. Enhanced bone regeneration by siliconsubstituted hydroxyapatite derived from cuttlefish bone. Clin Oral Impl Res 2017; 28: 49-56.

17. Dennymol P and Joseph R. Morphological diversity in nanohydroxyapatite synthesized from waste egg shell: verification and optimization of various synthesis parameters. Int J Sci Technol 2014; 2: 179.

18. Goloshchapov D, et al. Synthesis of nanocrystalline hydroxyapatite by precipitation using hen's eggshell. Ceram Int 2013; 39: 4539-4549. no.

19. Ellies LG, et al. Quantitative analysis of early in vivo tissue response to synthetic apatite implants. J Biomed Mater Res 1988; 22: 137-148.

20. Bigi A, et al. Chemical and structural characterization of the mineral phase from cortical and trabecular bone. J Inorg Biochem 1997; 68: 45-52.

21. Milovac D, et al. PCL-coated hydroxyapatite scaffold derived from cuttlefish bone: morphology, mechanical properties and bioactivity. Mater Sci Eng C 2014; 34: 437-445.

22. Florek M, et al. Complementary microstructural and chemical analyses of Sepia officinalis endoskeleton. Mater Sci Eng C 2009; 29: 1220-1226.

23. Petrauskaite $\mathrm{O}$, et al. Biomimetic mineralization on a macroporous cellulose-based matrix for bone regeneration. Biomed Res Int 2013; 2013: 1-9.

24. Petrauskaite O, Juodzbalys G, Viskelis P, et al. Control of the porous structure of cellulose-based tissue engineering scaffolds by means of lyophilization. Cellul Chem Technol 2016; 50: 23-30.

25. Hildebrand $\mathrm{T}$, et al. Direct three-dimensional morphometric analysis of human cancellous bone: microstructural data from spine, femur, iliac crest, and calcaneus. J Bone Miner Res 1999; 14: 1167-1174. no.

26. Kasaai MR. A review of several reported procedures to determine the degree of $\mathrm{N}$-acetylation for chitin and chitosan using infrared spectroscopy. Carbohyd Polym 2008; 71: 497-508.

27. Pina S, Oliveira JM and Reis RL. Natural-based nanocomposites for bone tissue engineering and regenerative medicine: a review. Adv Mater 2015; 27: 1143-1169. no.

28. Vallet-Regí M and Navarette DA. Nanoceramics in clinical use: from materials to applications. 2nd ed. Cambridge, UK: Royal Society of Chemistry, 2015.

29. Sopyan I, Mel M, Ramesh S, et al. Porous hydroxyapatite for artificial bone applications. Sci Technol Adv Mater 2007; 8: 116-123.

30. Poompradub S, Ikeda Y, Kokubo Y, et al. Cuttlebone as reinforcing filler for natural rubber. Eur Polym J 2008; 44: 4157-4164. no. 
31. Rocha J, et al. Scaffolds for bone restoration from cuttlefish. Bone 2005; 37: 850-857.

32. Oh SY, et al. Crystalline structure analysis of cellulose treated with sodium hydroxide and carbon dioxide by means of X-ray diffraction and FTIR spectroscopy. Carbohyd Res 2005; 340: 2376-2391. no.

33. Hsu J, et al. A comparison of micro-CT and dental CT in assessing cortical bone morphology and trabecular bone microarchitecture. PLoS One 2014; 9: e107545.

34. Feehan L, Buie H, Li L, et al. A customized protocol to assess bone quality in the metacarpal head, metacarpal shaft and distal radius: a high resolution peripheral quantitative computed tomography precision study. $B M C$ Musculoskeletal Disord 2013; 14: 367.

35. Renders G, Mulder L, Van Ruijven L, et al. Porosity of human mandibular condylar bone. J Anat 2007; 210: 239-248.

36. Lansdown A, Sampson B and Rowe A. Sequential changes in trace metal, metallothionein and calmodulin concentrations in healing skin wounds. J Anatomy 1999; 195: 375-386.

37. Miramand P, Bustamante P, Bentley D, et al. Variation of heavy metal concentrations (Ag, $\mathrm{Cd}, \mathrm{Co}, \mathrm{Cu}, \mathrm{Fe}, \mathrm{Pb}$, $\mathrm{V}$, and $\mathrm{Zn}$ ) during the life cycle of the common cuttlefish Sepia officinalis. Sci Total Environ 2006; 361: 132-143.

38. Al Farraj S, El-Gendy AH, Alyahya H, et al. Heavy metals accumulation in the mantle of the common cuttlefish sepia pharaonis from the Arabian Gulf. Aust $J$ Basic Appl Sci 2011; 5: 897-905.

39. Osredkar J and Sustar N. Copper and zinc, biological role and significance of copper/zinc imbalance. J Clinic Toxicol 2011; 3: 2161.

40. Bhattacharya PT, Misra SR and Hussain M. Nutritional aspects of essential trace elements in oral health and disease: an extensive review. Scientifica 2016; 2016: 1-12.

41. Drouet C, Carayon M, Combes C, et al. Surface enrichment of biomimetic apatites with biologically-active ions $\mathrm{mg} 2$ and $\mathrm{Sr}$ 2: a preamble to the activation of bone repair materials. Mater Sci Eng C 2008; 28: 1544-1550.

42. Bracci B, et al. Effect of $\mathrm{mg} \mathrm{2,} \mathrm{Sr} \mathrm{2,} \mathrm{and} \mathrm{Mn} 2$ on the chemico-physical and in vitro biological properties of calcium phosphate biomimetic coatings. $J$ Inorganic Biochem 2009; 103: 1666-1674. no.

43. Salma-Ancane K, et al. Incorporation of magnesium ions into synthetic hydroxyapatite: synthesis and characterization. Key Eng Mater 2013; 527: 26-31.

44. Dermience M, Lognay G, Mathieu F, et al. Effects of thirty elements on bone metabolism. J Trace Elem Med Biol 2015; 32: 86-106.

45. Demidenko V, Lazarev A and Konoplya A. Immuno rehabilitation of patients with the complicated chronic salpingo-oophoritis in the postoperative period. Курский Научно-Практический Вестник 2007; 52: 52-58.
46. Lekhanova EN, Kiriliuk LI and Romanova I. Efficiency of food supplements rich of mineral substance in complex therapy of hypertensive disease in the far north. Voprosy Pitaniia 2007; 76: 65-68.

47. Gavril'eva KS, et al. Influence of electrophoresis of antler mass on restorative processes in young athletes during the preparatory period of a one-year training cycle. Int $J$ Biomed 2016; 6: 78-81.

48. Basaki M, Saeb M, Nazifi S, et al. Zinc, copper, iron, and chromium concentrations in young patients with type 2 diabetes mellitus. Biol Trace Elem Res 2012; 148: 161-164.

49. Jha RK and Zi-Rong X. Biomedical compounds from marine organisms. Marine Drugs 2004; 2: 123-146.

50. Poh PS, Hutmacher DW, Stevens MM, et al. Characterization of bioactive glass composite scaffolds for bone regeneration. Biofabrication 2013; 5: 045005.

51. Florencio-Silva R, et al. Biology of bone tissue: structure, function, and factors that influence bone cells. Biomed Res Int 2015; 2015: 421746.

52. Wang $\mathrm{C}$, et al. Bone microstructure and regional distribution of osteoblast and osteoclast activity in the osteonecrotic femoral head. PLoS One 2014; 9: e96361. no.

53. San Thian E, et al. The response of osteoblasts to nanocrystalline silicon-substituted hydroxyapatite thin films. Biomaterials 2006; 27: 2692-2698. no.

54. Landi E, et al. Biomimetic Mg-substituted hydroxyapatite: from synthesis to in vivo behaviour. J Mater Sci 2008; 19: 239-247. no.

55. Szcześ A, Hołysz L and Chibowski E. Synthesis of hydroxyapatite for biomedical applications. Adv Colloid Interf Sci 2017; 249: 321-330.

56. Liuyun J, Yubao L and Chengdong X. Preparation and biological properties of a novel composite scaffold of nano-hydroxyapatite/chitosan/carboxymethyl cellulose for bone tissue engineering. J Biomed Sci 2009; 16: $65-75$.

57. Tao K, Mao T, Chen F, et al. The preparation of a new hydroxyapatite and the study on its cytocompatibility. J Biomed Eng 2006; 23: 887-890.

58. Anderson HC. Molecular biology of matrix vesicles. Clin Orthopaed Relat Res 1995; 314: 266-280.

59. Clover J and Gowen M. Are MG-63 and HOS TE85 human osteosarcoma cell lines representative models of the osteoblastic phenotype?. Bone 1994; 15: 585-591.

60. Lebourg M, Anton JS and Ribelles JG. Hybrid structure in PCL-HAp scaffold resulting from biomimetic apatite growth. J Mater Sci 2010; 21: 33-44.

61. Zhang Y, et al. Enhanced biomineralization in osteoblasts on a novel electrospun biocomposite nanofibrous substrate of hydroxyapatite/collagen/chitosan. Tissue Eng Part A 2010; 16: 1949-1960. 